\title{
A STUDY OF AUDIO TAPE
}

Noel K. Reen

Purdue University

EDITOR'S NOTE: The information reported herein is the first of a two-party study conducted by the Purchasing Department of Purdue University to provide further information about various audiotapes for the consumer. Part I of the report, included herein, reveals the results of various analyses of tapes in the cassette format. Part II of the report, to appear in a forthcoming issue of NALLD JOURNAL, will present similar information for reel tapes.

\section{INTRODUCTION}

A review of current literature would show test results for a series of tape tests, all conducted by different test laboratories with varying test procedures and apparatus. With no common data base, it is impossible to compare test data and come to a valid conclusion on the type of audio tape which should be used in any given application.

This study provides a common data base with which to compare both reel and cassette tape, for signal-to-noise ratio, total harmonic distortion, dynamic response, frequency response, bias and virgin noise, and oxide coating uniformity. Testing has been divided into two classes, reel and cassette, as each class of tape requires slightly different input signal levels and test frequencies. It should be em. phasized that comparison of tapes within a class is valid, but comparison of tapes between classes is not valid, due to the differing test conditions.

In an attempt to identify test tape recorders with the widest bandwidth and the highest signal-to-noise ratio, test data developed by CBS Laboratories for all available recorders was evaluated. The cassette recorder selected was the Nakamichi Model 700 unit, while the Pioneer Model RT1050 reel unit was chosen.

Test samples were solicited from distributors and manufacturers, with test facilities and some of the test equipment loaned by University departments. The test recorders and specialized test equipment were loaned by sources outside the University. 
Before testing began, standard testing procedures were developed and written to insure comparative validity and accuracy. Each phase of the tests was completed on all tapes at the same time to insure consistency of results. All test results were modified by the appropriate correction factors to account for impedance mismatches between the test recorders and test instruments.

The primary intent of the study was to identify differences between tapes in each class, rather than their actual performance in the test tape deck. Therefore, bias and equalization settings, where variable, were adjusted for standard tape, rather than optimizing each tape as it was tested.

\section{APPARATUS AND TEST PROCEDURE}

For cassette tests, tapes were arbitrarily divided into two classes, ferric oxide and chromium dioxide, as both were available. Tapes with high energy or doped formulations were included with ferric oxide tapes. The correction factor for impedance mismatch, + I.65 $\mathrm{Db}$., is applied to all measurements.

\section{TEST EQUIPMENT}

1. Nakamichi Model 700 cassette recorder

2. General Radio Model 1523-P2 graphic level recorder with sweep oscillator

3. Jeolco Model JSM-U3 scanning electron microscope

4. General Radio Model 1932 A distortion and noise analyzer

5. Hewlett Packard Model 400L Vacuum tube voltmeter

6. General Radio Model 1310 sine wave oscillator

7. General Radio Model 1192B electronic counter

8. Model I dropout counter analyzer (Purdue Built)

\section{TEST PROCEDURE}

To evaluate cassette audio tape, tests were performed to identify the following characteristics:

SIGNAL-TO-NOISE-RATIO-Measured as the difference between the biased noise level of each tape, with signal input shorted, and that input level which causes 3\% Total Harmonic Distortion to be recorded at the output.

With the VTVM set to read $\mathrm{Db}$., and connected to the test recorder line output, the test recorder is set to the record mode, with the monitor switch in tape position. The results are shown in Table I as Biased Tape Noise.

With the sweep oscillator set to $333 \mathrm{~Hz}$, the Distortion and Noise Analyzer is calibrated and adjusted to read total harmonic distortion, and is then connected to the test recorder line output. The sweep 


\section{Audio Tape}

oscillator is connected to the test recorder output, and with the recorder set to the record mode and the monitor switch set to tape position, the tone is recorded. The input level of the test recorder is adjusted until the Distortion and Noise Analyzer reads 3\% THD. With the test recorder running, the Distortion and Noise Analyzer is disconnected ond the VTVM reconnected. The results are listed in Table 1 as 3\% THD Level, DB.

The algebraic difference between the Biased Tape Noise level and the 3\% THD Level is the Signal-To-Noise Ratio, and is shown in Table 1 for the tape under test.

TOTAL HARMONIC DISTORTION-Measured by recording a $333 \mathrm{~Hz}$ tone at $-20 \mathrm{Db}$ reference level, and obtaining the Total Harmonic Distortion from the Distortion and Noise Analyzer.

The Distortion and Noise Analyzer is calibrated and adjusted to $333 \mathrm{~Hz}$, after connection to the sweep oscillator which is set to the test frequency. After connecting the sweep oscillator to the input, and the Distortion and Noise Analyzer to the line output of the test recorder the recorder is set to record mode.

With the test recorder monitor switch set to tape, and the test recorder input level set to $-20 \mathrm{Db}$., the tone is recorded.

The Distortion and Noise Analyzer will read Total Harmonic Distortion, and results are listed in Table 1.

By repeating the test at several frequencies, a Total Harmonic Distortion curve results. Figure 1 shows curves for fcur tapes, along with those for the test oscillator and test recorder.

DYNAMIC RESPONSE-Measured by recording a $333 \mathrm{~Hz}$ tone at an input level which results in $3 \%$ Total Harmonic Distortion at the test recorder line output.

The Distortion and Noise Analyzer is calibrated and adjusted to $333 \mathrm{~Hz}$ after connection to the sweep oscillator. With the sweep oscillator connected to the test recorder input, and the Distortion and Noise Analyzer connected to the line output, the test recorder is set to the record mode and with the monitor switch at tape position, records the tone.

The input level is increased until the Distortion and Noise Analyzer indicates $3 \%$ THD. With the test recorder running, the VTVM is connected in place of the Distortion and Noise Analyzer and the Dynamic Response, or Headroom, in $\mathrm{Db}$ as shown in Table 1 is read under the heading 3\% THD, Db.

FREQUENCY RESPONSE-Measured by recording a variable frequency tone having a range of $20 \mathrm{~Hz}$ to $20 \mathrm{KHz}$, at $-20 \mathrm{Db}$., and plotting the resultant response characteristics versus frequency. 
With the sweep oscillator connected to the input of the test recorder, the line output of the test recorder is connected to the input of the Graphic Level Recorder. With the VTVM connected to the test recorder line output, and the monitor switch in source position, the test recorder input level is adjusted for $\cdot 20 \mathrm{Db}$.

With the test recorder in the record mode and the monitor switch in tape position, the Graphic Level Recorder starts. When the response plot is complete, it will reset to the initial conditions automatically. Response plots for all tapes tested appear in Figures 2 and 3.

BIASED AND VIRGIN TAPE NOISE-Biased tape noise is measured by reading noise in $\mathrm{Db}$., produced by a tape recorded on the test recorder, with the signal input shorted. Virgin tape noise is measured by reading the noise produced by an un-recorded virgin tape played on the recorder with signal input shorted.

With the VTVM set to read $\mathrm{Db}$., and connected to the test recorder line output, the test recorder is set to record code with the monitor switch in the tape position. The results are recorded in Table 1 as Biased Tape Noise.

With the VTVM set to read $\mathrm{Db}$., and connected to the test recorder line output, the test recorder monitor switch is set to tape position. With the test recorder in the play mode, the Virgin Tape Noise is read on the VTVM and is listed in Table 1 as Virgin Tape Noise.

OXIDE COATING UNIFORMITY-Determined by evaluation of Scanning Electron Micrographs in the Jeolco and International Scientific Instruments electron microscopes.

After 1/2 inch segments of tape are mounted on the test blocks, they are vacuum coated to improve conduction characteristics. The samples are then put in the microscope for analysis.

Micrographs are obtained for each tape at magnification of $\mathrm{X}$ $1000, X 10,000$, and X 90,000, and evaluated for Oxide Coating Uniformity.

\section{SUMMARY OF RESULTS \\ AND CONCLUSIONS \\ CASSETTE TAPE}

A review of Table 1 shows that non-Dolby Signal-to-Noise Ratios vary only $3.7 \mathrm{Db}$. for the tapes tested. With Dolby on, the two tapes tested showed an average of $5.5 \mathrm{Db}$. improvement in Signal-to Noise Ratio.

As some work was done with the Dolby noise reduction system, an illustration of the Dolby principle is shown in Figure 4. For an 


\section{Audio Tape}

input of $-30 \mathrm{Db}$., $-20 \mathrm{Db}$., is recorded at the higher frequencies. Then, in playback, the $20 \mathrm{Db}$., level is reduced to $-30 \mathrm{Db}$., accompanied by a marked drop in high frequency noise, or hiss. This results in the im. proved Signal-to Noise Ratio, shown in Table 1.

An analysis of Table 2 would show a tendency for Total Harmonic Distortion to decrease as frequency increases. Total Harmonic Distortion is higher at frequencies of $1 \mathrm{KHz}$ and lower as more acoustic energy is transferred to the tape oxide during the recording process. The stronger magnetic flux more easily saturates the tape oxide layer than does the weaker flux of a higher frequency. For example, at 16 $\mathrm{KHz}$ the flux may not penetrate to the full depth of the oxide layer, while at $2 \mathrm{KHx}$ the magnetic flux is of such a strength as to fully penetrate the oxide layer, over-saturating the oxide coating and causing distortion.

For derived sinusoidal waveforms, distortion exists and the magnitude is dependent on the method of generation. It can be shown that the most significant component of harmonic distortion is that of the third harmonic. Ideally, one should test for this component but, practically, the harmonic distortion and noise analyzer provide the total contribution of all harmonics, with the fundamental absent.

Tab'e 2 shows the range of average Total Harmonic Distortion for the tested tapes to be $0.035 \%$ for ferric oxide types. Chromium dioxide tapes had an average Total Harmonic Distortion range of only $0.015 \%$, about $29 \%$ better than ferric tapes.

As a reference, Total Harmonic Distortion for the sweep generator, and the test recorder, is shown in Table 3. For the sweep generator, the average THD is $0.119 \%$, while the test recorder had an average THD of $0.019 \%$. The total average contribution by these two instruments to Total Harmonic Distortion is only $0.138 \%$, so calculation would show that the contribution to THD by only the tape under test is minimal, only about one third of the total average THD.

Although the Dynamic Response or Headroom of all tapes varied no more than $3.8 \mathrm{Db}$., three samples showed significantly improved performance with each above $+10 \mathrm{Db}$. at the test frequency. And though Table 1 indicates relatively small variations in Dynamic Response, it is evident that the chromium dioxide tapes have better signal-to-noise ratios, due to improved biased noise characteristics.

Had time permitted the measurement of Dynamic Response of all tapes at several frequencies, the results would probably have been similar to that shown in Table 4 and Figure 5 , where one tape was evaluated at frequencies from $333 \mathrm{~Hz}$ to $8 \mathrm{KHz}$. It is evident that with increasing frequency, Dynamic Response characteristics seriously degrade. Although magnetic flux is much less than at the lower fre- 
quencies, excessive recording levels at high frequencies will cause a greatly increased total harmonic distortion which may be accompanied by self erasure ard is evidenced by an apparent loss in high frequency response.

Frequency Response characteristics for the test tapes, the test recorder, and the graphic level recorder are shown in Figure 2 and 3. The test recorder demonstrates virtually no response abberations over the audio frequency range, permitting the recording of only the tape response without need for a correction factor.

The vertical scale in all Frequency Response is $5 \mathrm{Db}$. per major division, with all curves origination at $20 \mathrm{~Hz}$. The relative position of each curve from $0 \mathrm{Db}$. is indicative of tape sensitivity, as the record level was continuously monitored at $.20 \mathrm{Db}$. to avoid the possibility of tape saturation and consequent distortion.

The frequency Response curves for three types of chromium dioxide tape are within $1 \mathrm{Db}$. from $60 \mathrm{~Hz}$ to $20 \mathrm{KHz}$. Because of this extended response characteristic, the typical droop in response for ferric oxide tapes, beginning at about $2 \mathrm{KHz}$, does not occur when recording with chromium dioxide tape.

Several Frequency Response curves exhibit abberations at high frequencies, absent in the other plots.

Biased Tape Noise, on an average, is about $2 \mathrm{Db}$. greater than Virgin Tape Noise, as seen in Table 1. While Virgin Tape Noise is the residual noise of the tape oxide, when played on the test recorder, Biased Tape Noise is the contribution to noise by the test recorder bias oscillator. Practically, it is Biased Tape Noise which is of primary concern since it is the reference level for determination of the signal. to-noise ratio of a tape.

It is evident that chromium dioxide tape has about $2.5 \mathrm{Db}$. lower biased tape noise that its ferric oxide counterpart, yielding higher signal-to-noise ratios.

Virgin Tape Noise, the base figure for all tape noise measurements, varies no more than $0.9 \mathrm{Db}$. for all ferric oxide tapes tested and no more than $0.8 \mathrm{Db}$. for the chromium dioxide tapes checked.

Oxide Coating Uniformity could not be determined due to insufficient time for experimentation.

\section{CONCLUSIONS}

Results of the study indicate there are only minor variations in Signal-to-Noise Ratio, Total Harmonic Distortion, Dynamic Response and Biased and Virgin Tape Noise of the 23 types of cassettes tested.

Frequency response characteristics are variable, and it is sug. gested that a tape user review the test curves to identify a tape to 
fit the intended application. For those needs where only slight abberations over the entire audio spectrum can be tolerated, the obvious choice is a chromium dioxide tape. If an application requires recording signals up to $3 \mathrm{KHz}$, then the response plots can assist in selection of a tape with only the needed response characteristic.

The user must also consider the Dynamic Response and Signalto-Noise Ratio to insure that the best tape is chosen in the application, combined with the greatest economy. If wide dynamic ranges are anticipated in recording then the user must carefully consider the Dynamic Range characteristics so as to avoid saturation of the tape oxide and the resulting distortion.

\section{APPENDIX A LIST OF DEFINITIONS}

SIGNAL-TO-NOISE RATIO (S/N): The difference between bias noise level, in $\mathrm{Db}$., and the 3\% Total Harmonic Distortion level, in $\mathrm{Db}$.

TOTAL HARMONIC DISTORTION (THD): The total contribution of all harmonics to distortion, expressed as a percent of the fundamental reference frequency, when fundamental frequency is absent.

DYNAMIC RESPONSE (HEADROOM): That input level which results in 3\% Total Harmonic Distortion in the output, measured at a reference frequency.

FREQUENCY RESPONSE: The deviation in output characteristics over the range of $20 \mathrm{~Hz}$ to $20 \mathrm{KHz}$, in response to a constant input reference level.

BIAS AND VIRGIN TAPE NOISE: That output resulting from the recording process, with a zero audio signal input, and that output resulting from the playing of an unrecorded, virgin tape.

OXIDE COATING UNIFORMITY: That quality of oxide deposition on the tape base, as determined by evaluation of scanning electron micrographs. 
Capitol Mustc Tape $4 \dot{5}$

$-43.2$

$-41.2$

...........

$7: 7$

48.9

$-42.8 \quad \cdots \cdots \cdots \cdots \cdots \cdots,-40.8$

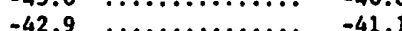

$8.6 \ldots \ldots \cdots \cdots \cdots \cdots \cdots \quad 49.8$

Capitol $\# \mathrm{r}, \mathrm{C60}$

51.4

Sony Plus 2 , 660

$-42.8$

Maxell IN C60.

TDK D, C60

$-42$.

$-41$.

$\ldots \ldots \ldots \ldots .10 .6$

48.8

White Box

$-42.6 \quad \cdots \cdots \cdots \cdots \cdots \cdots \cdots$

$8.7 \ldots \ldots \ldots \ldots \ldots \cdots, \quad 48.8$

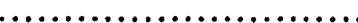

$-42.7$

$-42.3$

$-40.9$

$\ldots \ldots \ldots \ldots+7.7$

48.4

Memorex $\mathrm{MRX} 2, \mathrm{C} 60$

Maxel1 UD, C60

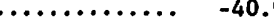

$7.6 \ldots$

ASP SK, 600

TDK, ED, C9O

$-43.0 \quad \ldots \ldots \ldots \ldots \ldots \ldots-41$.

8.6

$-42$.

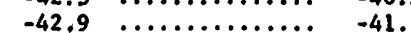

$\ldots \ldots \ldots \ldots \quad 9.1 \ldots \ldots \ldots \ldots . .49 .4$

$-42.3 \quad \ldots \ldots \ldots \ldots \ldots \ldots .6 .40 .3$

$-42.5 \quad \ldots \ldots \ldots \ldots \ldots \ldots,-40.7$

Scotch Classic.

Tracs Plus HE, $\mathrm{C} 60$

Certron HE 60

Certron HE 60 (Dolby On)

Advent $\mathrm{CRO}_{2}, \mathrm{C6O}$

$-43.0$

-40.7
-41.2

$\ldots \ldots \ldots \ldots . \quad 8.4 \ldots \ldots \ldots \ldots \ldots .49 .5$

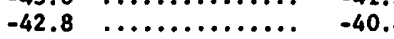

$\begin{array}{lll}-42.6 & \cdots \cdots \cdots \cdots \cdots \cdots & -40.6\end{array}$

......... 9.2

$4 \ldots \ldots \ldots \ldots \ldots 4.1$

Certron $\mathrm{CRO}_{2}, \mathrm{CD}-60$

Memorex $\mathrm{CRO}_{2}, \mathrm{KRC}$

Scotch $\mathrm{CRO}, \mathrm{C9O}$

Scotch $\mathrm{CrO}^{2}, \mathrm{C9O}$ (Dolby On)

Capitol Muzic Tape 60

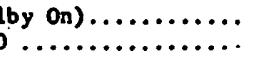

$\begin{array}{llll}-51.6 & \ldots & \ldots \ldots \ldots \ldots \ldots & -47.6\end{array}$

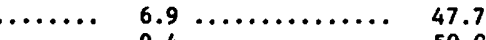

$\begin{array}{llll}-46.8 & \ldots \ldots \ldots \ldots \ldots \ldots & -43.3\end{array}$

$\begin{array}{llll}-46.9 & \ldots \ldots \ldots \ldots \ldots \ldots & -43.5 \\ -46.1 & \ldots \ldots \ldots \ldots \ldots \ldots & -43.1\end{array}$

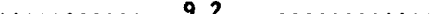

$-46.7 \quad \ldots \ldots \ldots \ldots \ldots \ldots-4,-43.2$

$-46.6 \quad \ldots \ldots \ldots \ldots \ldots . .4 .43 .3$

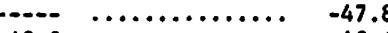

$\ldots \ldots \ldots \ldots, \quad 7.2 \ldots \ldots \ldots \ldots \ldots, \quad 50.7$

$\ldots \ldots \ldots \ldots, \quad 8.1 \ldots \ldots \ldots \ldots \ldots, 51: 2$

$\ldots \ldots \ldots \ldots \ldots \ldots \ldots \ldots+51.6$

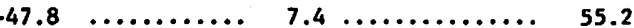

$-42.9 \quad \ldots \ldots \ldots \ldots \ldots \ldots,-40.6$

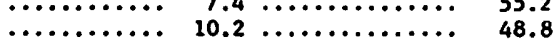

TABLE 1

Virgin and Biased Tape Noise, 3\% THD, and Signal-to-Noise Ratio 
TABLE 2

Total Harmonic Distortion Variation with Change in Frequency, (-20Db.)

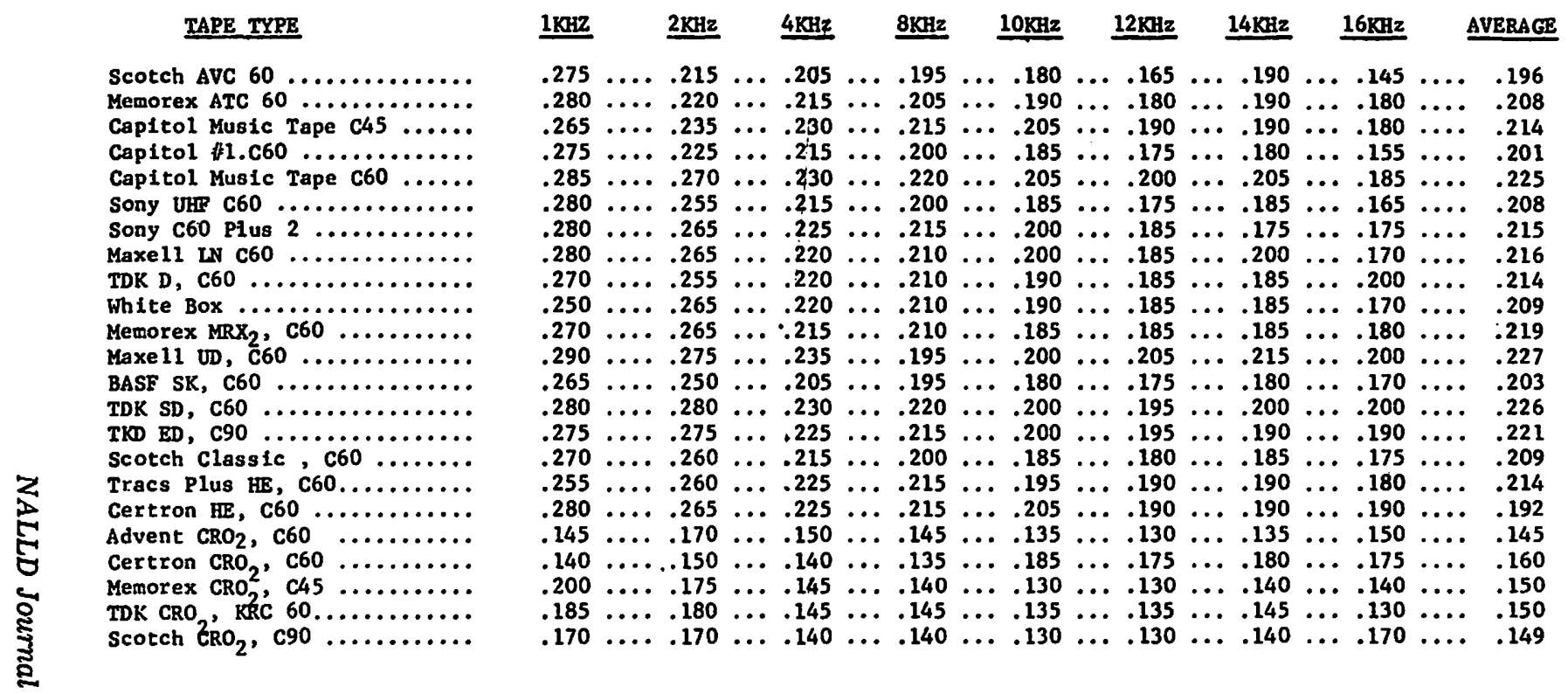


TABLE 3

Total Harmonic Distortion, Test Oscillator and Test Recorder

\begin{tabular}{|c|c|c|c|c|c|c|c|c|c|c|}
\hline EQUIPMENT & $333 \mathrm{H} .2$ & $\underline{1 \mathrm{KHz}}$ & $\underline{2 \mathrm{KHz}}$ & $\underline{4 \mathrm{KHz}}$ & $\underline{8 \mathrm{KHZ}}$ & $10 \mathrm{KHz}$ & $12 \mathrm{KHz}$ & $14 \mathrm{KHz}$ & $16 \mathrm{KHz}$ & AVG. \\
\hline $\begin{array}{l}\text { General Radio Mod. } \\
1310 \text { Osetllator (ODB.) }\end{array}$ & .110 & .105 & .110 & .095 & .130 & .130 & .128 & .130 & .140 & .119 \\
\hline $\begin{array}{l}\text { Nakamichi Mod. } 700 \\
\text { Recorder }(-2: 0 \mathrm{Db} .)\end{array}$ & .038 & .028 & .020 & .015 & .020 & .020 & .020 & .010 & .020 & . \\
\hline
\end{tabular}

TABLE 4

Dynamic Response Variation with Change in Frequency

3\% THD Leve1, Db., Re1 mw/600 ohm

$\underline{333 \mathrm{~Hz}} \quad \underline{\mathrm{KHZ}} \quad \underline{2 \mathrm{KHz}} \quad \underline{4 \mathrm{KHz}} \quad \underline{\mathrm{KHz}}$

$\begin{array}{lllll}7.7 & 5.4 & 4.7 & 3.1 & -8.3\end{array}$




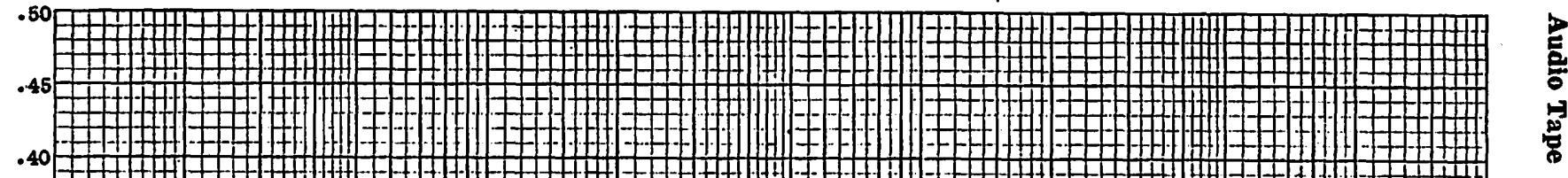

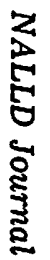

‘

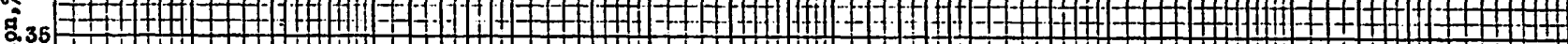

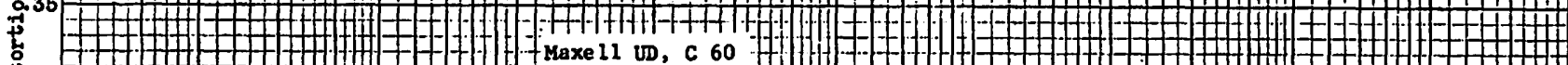

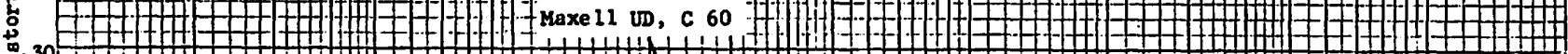
总.30

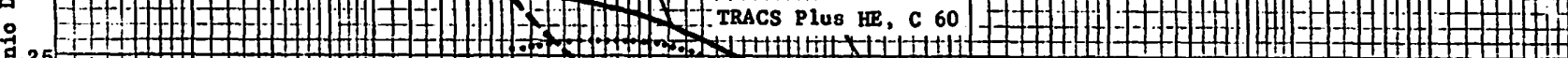
:.25 $\mathrm{L}$

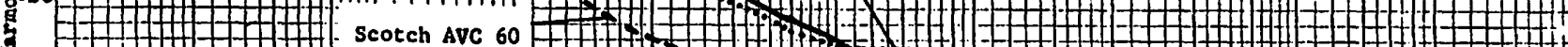

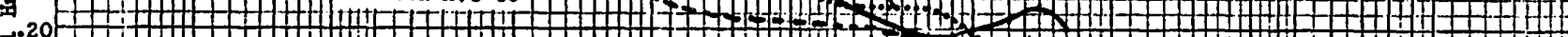
官 s. .16 $\frac{1}{-}$ G1310

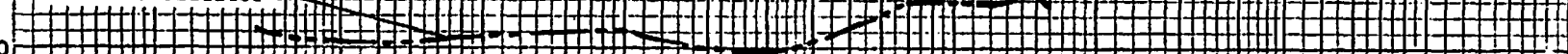
.10 壾

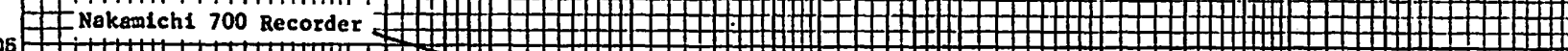

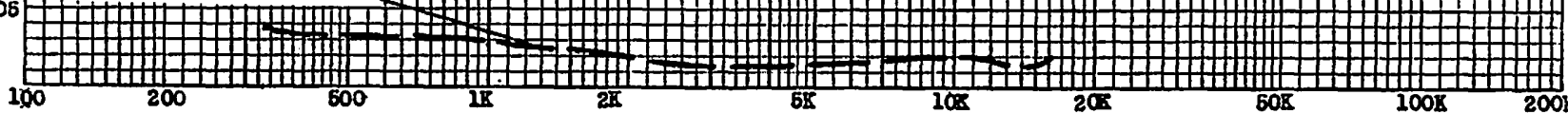
FREQUENCY IN Hz

Figure 1

Typical THD Curves for Four Tapes, and the Test Oscillator and Recorder 
Audio Tape

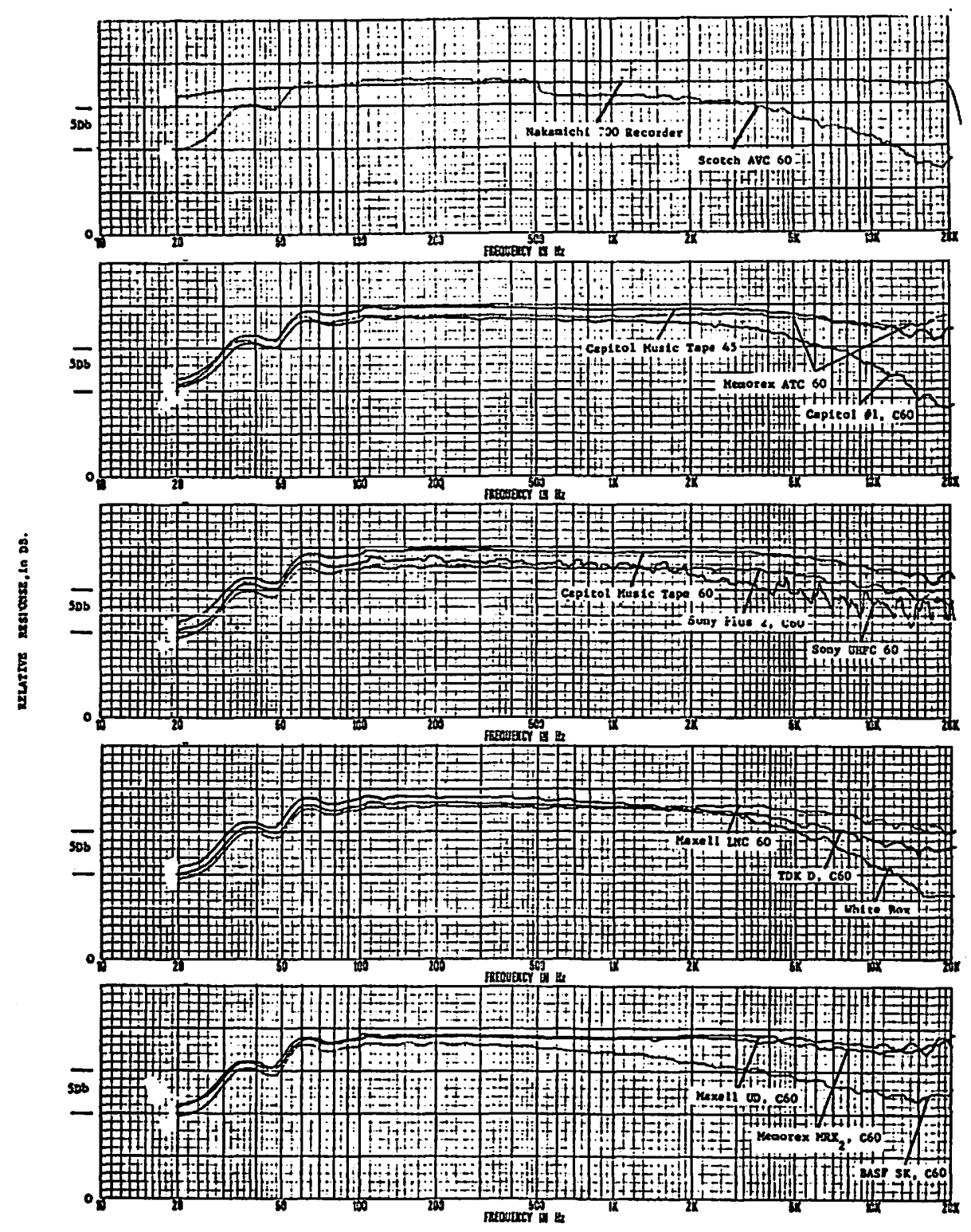

FIGURE 2

FREQUENCY RESPONSE, REEL TAPE 


\section{Audio Tape}
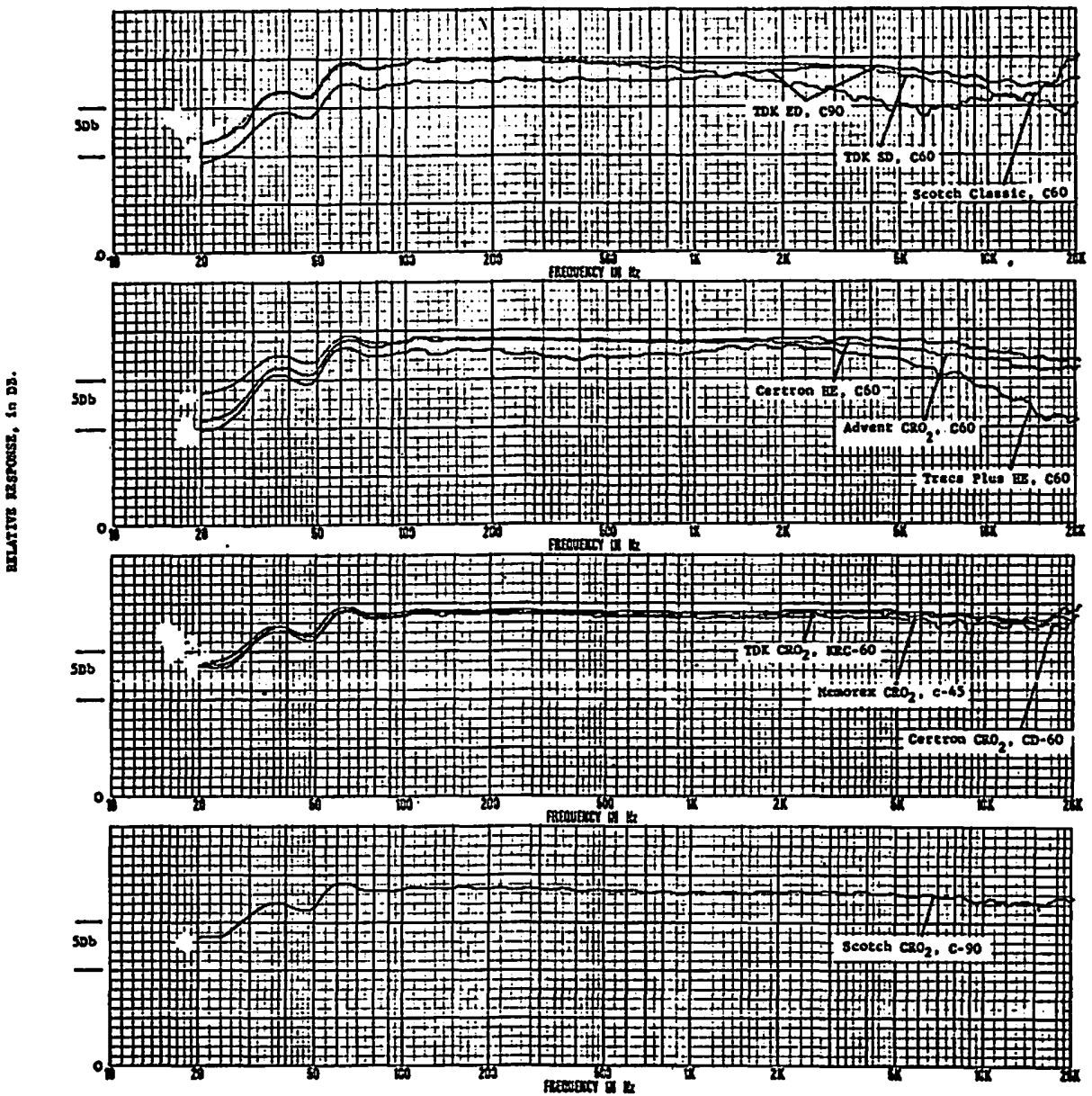

FIGURE 3

FREQUENCY RESPONSE, CASSETTE TAPE CONCLUSIONS 
Audio Tape

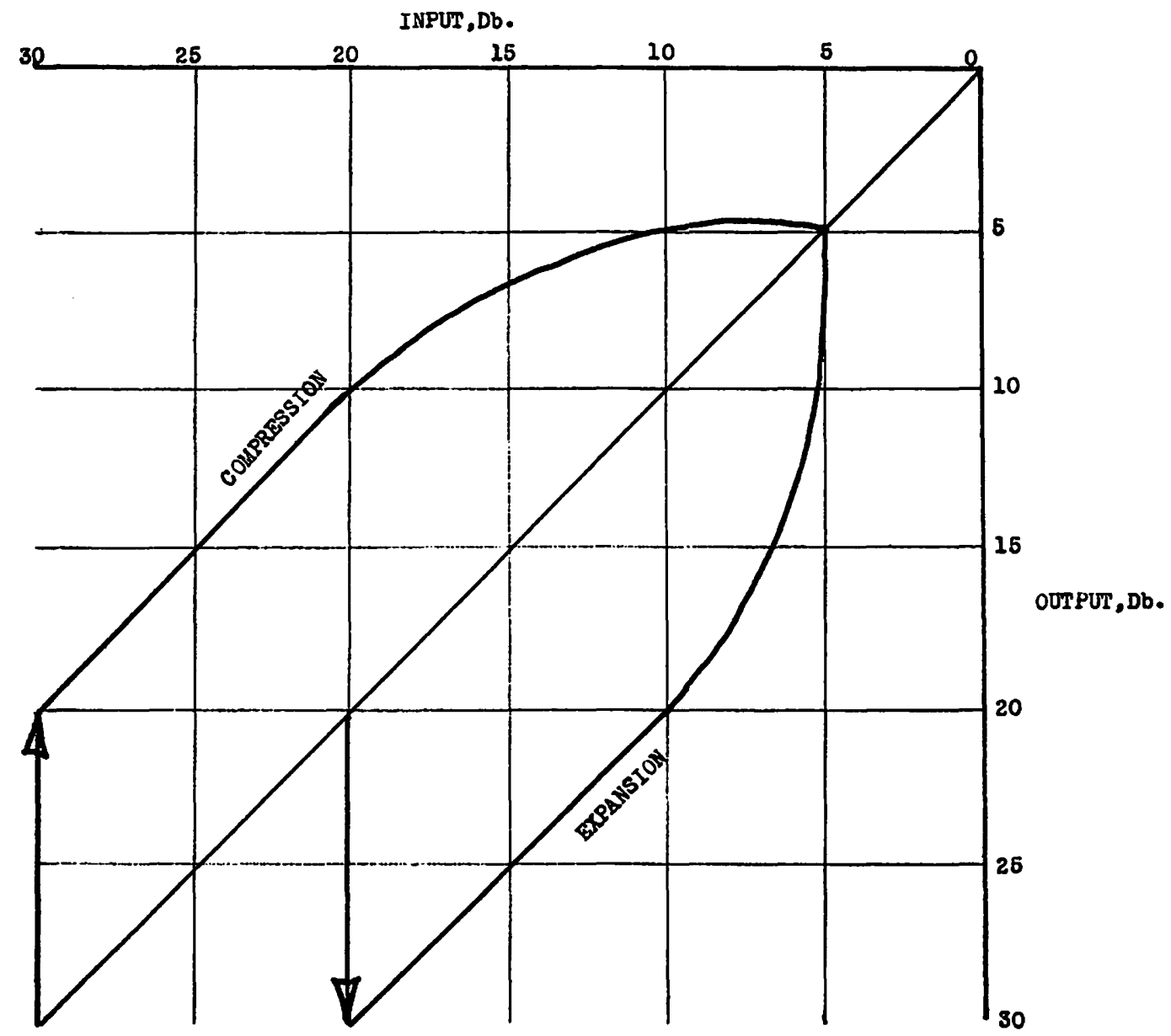

FIGURE 4

Dolby Transfer Characteristics 


\section{Audio Tape}

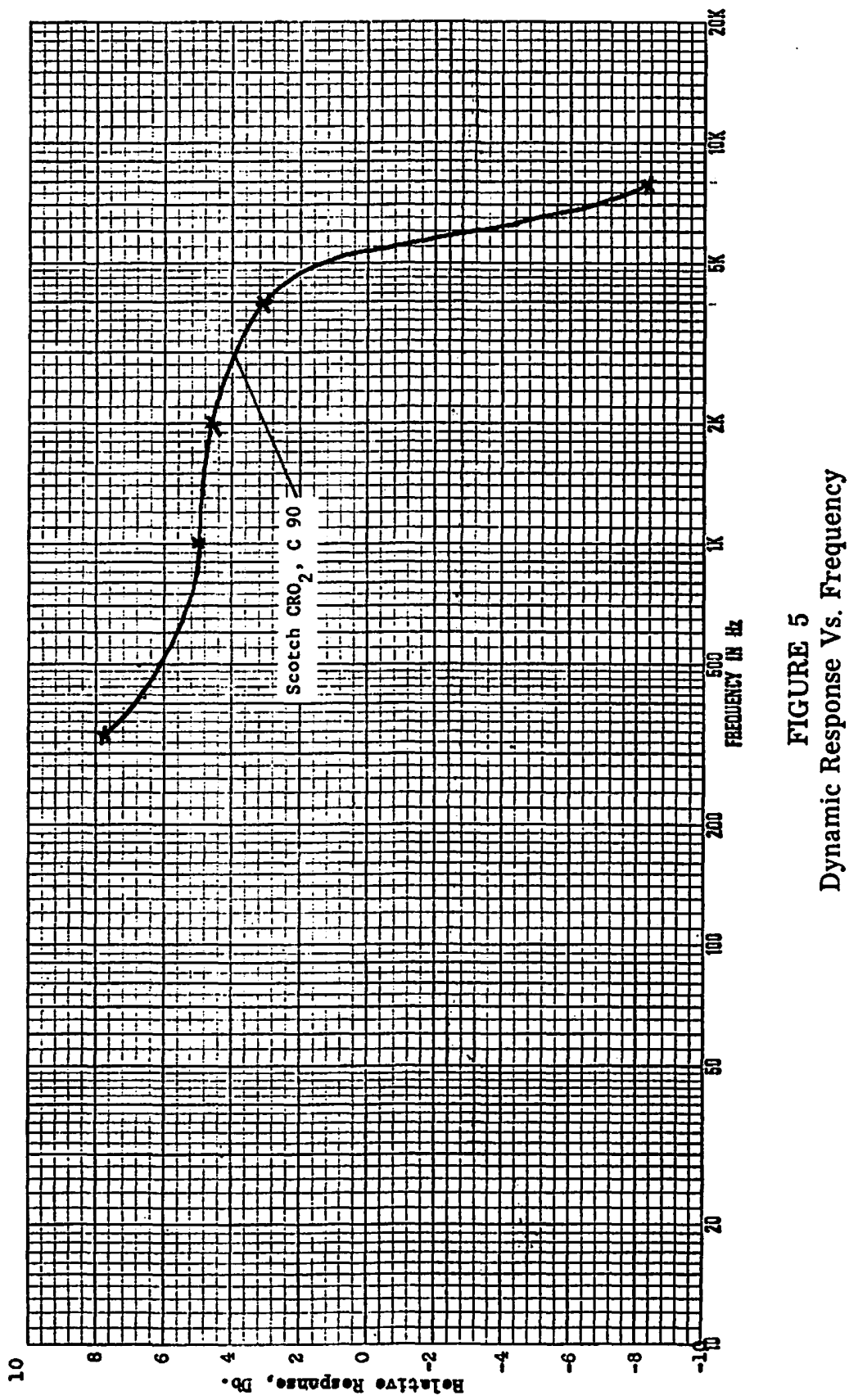


CPS Directory of Suppliers of Spanish Materials 1974, Cruzada Spanish Publications, Homestead, Florida 33030 ( $\$ 2.00$ per copy).

74-75 Catalog: Bilingual Educational Services, South Pasacena, California, 91030 .

A prime frustration of Spanish teachers derives from the fact that we live and work in fractured field. When we are not rhapsodizing over the diversified cultures of the entire Spanish-speaking world, we fall into depressing envy of the more compact single country cultures which seem to have neatly organized, readily available, well evaluated listings of greatly varied materials. So we grasp at every new compilation, hoping for something similar, that is, definitive. Here are two additions, neither definitive, but both helpful in the perplexing quest for Spanish materials.

The CPS Directory is an informational listing of suppliers, their addresses and specialties, which does not include individual articles or recommendations. The thirtyeight categories in the index include: Books, Games, Newspapers, Pen Pals, Records, Comic Books, Flags, Placement Bureaus, and Free Materials. All vary greatly in completeness. For example, the Book listing has seventy-three distributors, or presses, but only nine somewhat capricious University press selections. Weak categories are on Encyclopedias, the rather strange Professional Texts, Summer Schools Abroad (the recent listing and evaluation in Hispania is far superior), and the very incomplete Summer Schools in the U.S.A.-only seven are mentioned! Yet it is a very useful compendium combining a large variety of sources and materials not frequently found listed together. The scope is from elementary through college levels. It has good print and limited advertising. And it is certainly worth up-dating (for example, deleting the listing of the defunct Club de Libro) and augmenting. We commend the efforts and encourage an annual edition. 